\title{
Erectile Dysfunction and Associated Anxiety and Depression in Male Hemodialysis Patients: A Cross-Sectional Study at Karachi Institute of Kidney Diseases
}

\author{
Furqan Ahmad Jarullah ${ }^{1}$, Mahjabeen Yaseen ${ }^{2}$, Hassan Abdullah ${ }^{3,} 4$, Sadia Yaqoob ${ }^{1}$ \\ 1. Medicine, Jinnah Medical and Dental College, Karachi, PAK 2. Nephrology, Fazaia Ruth Pfau Medical College, \\ Karachi, PAK 3. Neurology, University of Alabama, Birmingham, USA 4. Medicine, Nishtar Medical University, Multan, \\ PAK
}

Corresponding author: Hassan Abdullah, dochassanabdullah@gmail.com

\section{Abstract \\ Objectives}

Chronic kidney disease (CKD) is one of the most prevailing diseases in the world and is associated with sequelae of depression, anxiety, and sexual dysfunction. The goal of our study is to measure the prevalence of erectile dysfunction, depression, and anxiety among patients suffering from CKD and to establish a correlation between them.

\section{Methodology}

The research was a single-centered, descriptive cross-sectional study. All male patients present at the time of the survey were interviewed, and then based on the inclusion and exclusion criteria, 84 were selected. The questionnaire comprised demographic variables, erectile function scoring using the International Index of Erectile Function (IIEF) scale, and Hospital Anxiety and Depression Scale (HADS) for depression and anxiety. All data were analyzed using SPSS Software 25.0 (IBM Corp., Armonk, USA).

\section{Results}

Out of 84 male patients, $47.6 \%$ had erectile dysfunction (ED). 10\% of the affected individuals had depression and $3 \%$ reported having anxiety. No known external factors had any contribution to erectile malfunction, depression, and/or anxiety.

\section{Conclusion}

We found no correlation of depression and/or anxiety with ED in this population of male subjects undergoing hemodialysis.

Review began 09/29/2020 Review ended 10/23/2020 Published 10/24/2020

๑) Copyright 2020

Jarullah et al. This is an open access article distributed under the terms of the Creative Commons Attribution License CC-BY 4.0., which permits unrestricted use, distribution, and reproduction in any medium, provided the original author and source are credited.
Categories: Internal Medicine, Nephrology

Keywords: hemodialysis, erectile dysfunction, depression, anxiety

\section{Introduction}

Chronic kidney disease (CKD) is an emerging crisis in the current time. According to a study published in December 2016 by the National Institute of Diabetes and Digestive and Kidney Diseases in the US, there is a $14 \%$ prevalence of CKD in the US citizens [1]. Due to very few studies conducted in this area in Pakistan, we have insufficient data to determine the actual prevalence of the disease. Chronic renal failure (CRF) is now a public health problem, mainly because of its prevalence, evolution, and the fact that it is the complete antonym of cost-effective and causes a financial burden on patients and the healthcare system [2]. The only two possible methods of treatment are lifelong hemodialysis or renal transplantation. As the majority of the population cannot afford renal transplants and the fact that very few donors are available, patients have no choice but to undergo hemodialysis as much as up to three times per week for 3-4 hours for the rest of their lives [3].

There have been reports of multiple obstacles that these patients have to face in their daily lives, apart from the physical and mental torture brought upon them by society. A common complaint that affects their quality of life is erectile dysfunction (ED). In 2014, approximately 150 million males were affected by ED worldwide and projected for numbers to double by 2025 [4]. It is defined as the persistent inability to achieve and/or maintain an erection enough for satisfactory sexual intercourse [5]. Scientists first documented in 1975 that erectile dysfunction was closely associated with hemodialysis [3]. It is said that a combination of organic and psychological factors is attributable to this condition in a human being [6]. Such factors required for normal erections include a complex balance of physiological, hormonal, neurological, and vascular 
factors, as well as emotional and social factors [7]. Sexual satisfaction, on the other hand, also seems to be a problem for these patients. Sexual gratification is defined as physical or emotional satisfaction provided by self-regulation [8].

ED is not only a medical problem but affects the marital relations and patient's self-esteem and causes the quality of life to decrease. which in turn causes the patient to go into depression or develop anxiety.

Considering all these circumstances and horrors the patients go through, many of them spiral their way into depression and anxiety. However, very few studies have been done to correlate ED with depression and anxiety. Since these conditions have such a vital impact on daily activities, it tends to falter the quality of life of these patients, indirectly declining it. It can be said confidently that in older patients, presentation for dialysis has a later onset, with numerous co-morbidities. It is believed that there is an increased risk of cognitive dysfunction, increased vulnerability to infections, and sensory impairments as well as functional and psychological dependence in these patients [9].

Objectively, this study was conducted to create, or rather, build the foundation to establish the link between sexual dysfunction in male patients who undergo hemodialysis and whether it has a connection with these patients undergoing anxiety and/or depression. Studies conducted so far have not been able to fill this gap in knowledge, especially in our developing country. Furthermore, Procci et al. observed that sexual dysfunction is not associated with primary kidney disease [10]. Hence, one other purpose to conduct this research was to follow up on his vision since a lot has changed since 1981 [10].

\section{Materials And Methods}

\section{Study setting}

This study was conducted in the setting of the Karachi Institute of Kidney Diseases located in the Federal B Area of Karachi, Pakistan.

\section{Subjects, sample size, and data analysis}

The study design selected was cross-sectional and it was conducted in November 2019. Our study includes adults who were suffering from chronic kidney disease and were undergoing hemodialysis in this institute. All male patients within that institute undergoing renal replacement therapy were surveyed. A total of 107 males were admitted at that time. Only 84 participants were included in this study as per the inclusion and exclusion criteria mentioned later. We used SPSS version 25.0 to analyze our data.

\section{Data collection tools}

A questionnaire was developed which contained questions regarding socio-demographic data, depression, and anxiety scoring according to Hospital Anxiety and Depression Scale (HADS), and sexual dysfunction scoring according to the International Index of Erectile Function (IIEF) [11].

Relevant socio-demographic data included age, number of children, occupation, duration of CRF and hemodialysis, number of dialysis sessions per week, and recent blood work including levels of hemoglobin, calcium, and phosphorous. HADS scale includes seven questions each for assessment of anxiety and depression. IIEF scale assesses sexual function by a series of 15 questions divided into five domains, namely erectile function, orgasmic function, sexual desire, intercourse satisfaction, and overall satisfaction.

\section{Inclusion and exclusion criteria}

Married males of 18 years or older were included in this study. Any participant who was under the legal age of marriage, which is 18 years (in Pakistan), unmarried, has not been living with their spouse for at least last one month, widower, suffering from severe co-morbidity such as paralysis or psychiatric disease, and demised during the study were excluded.

\section{Ethical considerations}

Each interview began with careful consideration of privacy and verbal informed consent that the questions asked will not be disclosed to anyone. A letter of approval was taken from the ethics committee of the institute.

\section{Results}

Among the 84 men, concerning the International Index of Erectile Function (IIEF), erectile dysfunction (ED) prevailed in 40 (47.6\%). The average age of the total sample was $48.7 \pm 12.5$ years, whereas those with ED had an average age of $51.1 \pm 12.5$ years, the youngest being at an age of 27 years and the oldest being 74 years of age. 27 (67.5\%) of the affected individuals seemed to have severe ED. The mean of the total IIEF score was $47.4 \pm 20.0$.

Table 1 shows the demographics and clinical parameters of patients enrolled in the study. 


\section{Cureus}

\section{Variables}

Patients demographics

Age (years) mean \pm SD

$48.7 \pm 12.5$

BMI $\left(\mathrm{kg} / \mathrm{m}^{2}\right)$ mean $\pm \mathrm{SD}$

$23.9 \pm 4.5$

Duration of hemodialysis (years) mean \pm SD

$2.32 \pm 2.4$

Cause of renal failure (\%)

Diabetes mellitus

Hypertension

57.1

Glomerulonephritis

6

Renal stone disease

NSAIDs

Cystic kidney disease

Other diseases (\%)

Hepatitis B

Hepatitis C

Cardiovascular diseases

Patient clinical characteristics

$\mathrm{Hb}(\mathrm{g} / \mathrm{l})$

Calcium (mmol/l)

Phosphorous (mmol/l)

$5.14 \pm 1.8$

Albumin (g/l)

$3.9 \pm 0.89$

\section{TABLE 1: Demographics and clinical parameters of patients}

NSAIDS: non-steroidal anti-inflammatory drugs; Hb: hemoglobin

Their mean age was $48.7 \pm 12.5$ years, while the average duration of hemodialysis was $2.32 \pm 2.4$ years. It was also seen that 28 (70\%) of the affected individuals were anemic, whereas 33 (75\%) of the individuals who did not have ED were anemic. Pearson's correlation was done for this particular variable, and that too was seen to be inconsequential (Table 2). 


\section{Cureus}

\section{Correlations}

$\begin{array}{llll} & & \text { Anemia } & \text { Erectile dysfunction } \\ \text { Anemia } & \text { Pearson Correlation } & 1 & .056 \\ & \text { Sig. (2-tailed) } & & .613 \\ & \mathrm{~N} & 84 & 84 \\ & \text { Pearson Correlation } & .056 & 1 \\ \text { Erectile dysfunction } & \text { Sig. (2-tailed) } & .613 & \\ & \mathrm{~N} & 84 & 84\end{array}$

\section{TABLE 2: Correlational analysis of anemia with erectile dysfunction}

A total of $16.8 \%$ of the participants had depression, of which only $10 \%$ were suffering from ED. Anxiety, however, prevailed in $14.3 \%$ of the study population and about $7.5 \%$ had erectile dysfunction. Figure 1 and Figure 2 show the frequency of depression and anxiety in the study participants, respectively.

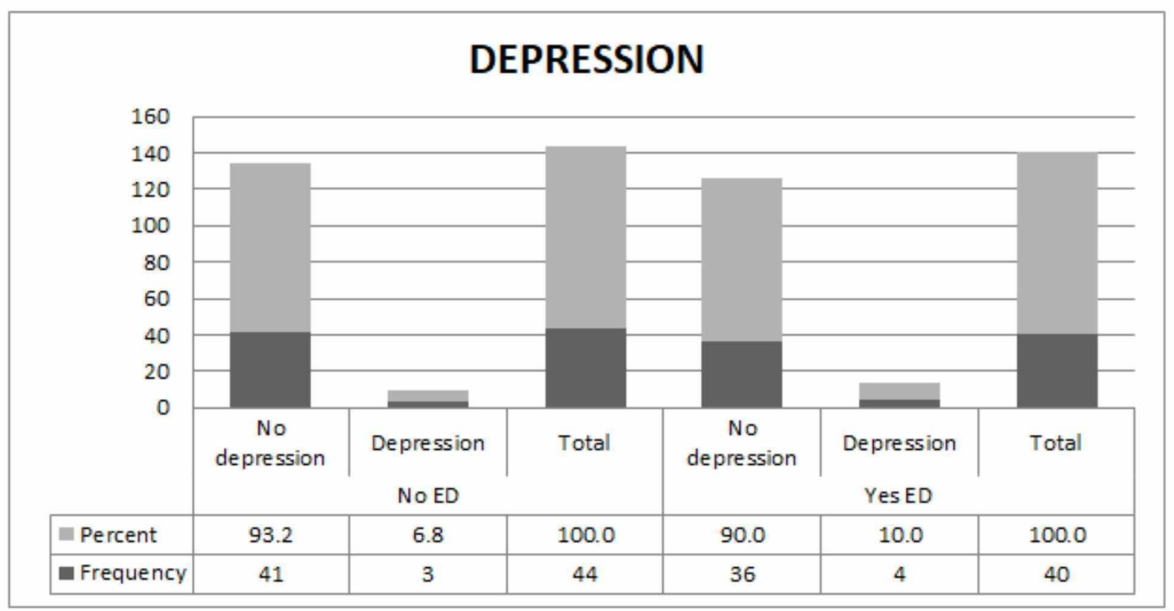

\section{FIGURE 1: Frequency of depression in the study participants}

ED: erectile dysfunction

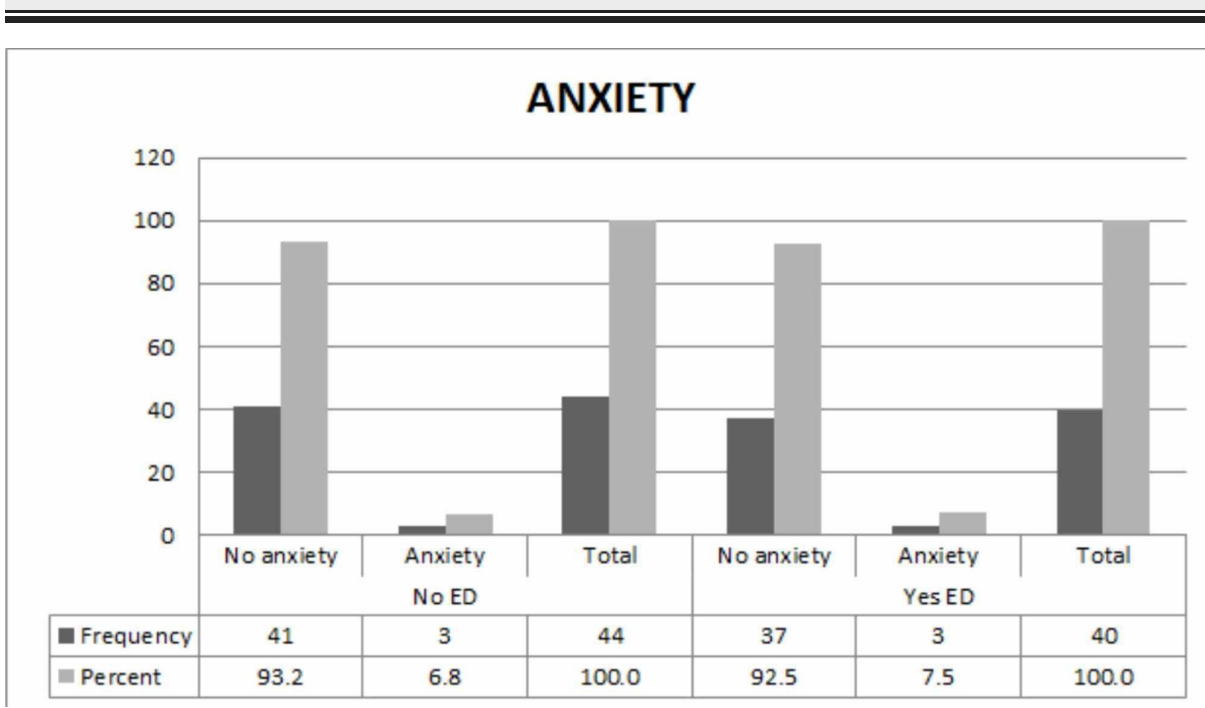




\section{Cureus}

FIGURE 2: Frequency of anxiety in the study participants

ED: erectile dysfunction

Pearson's correlation suggests a positive correlation, but $\mathrm{p}$-values were negligible with the values being 0.905 and 0.603 for anxiety (Table 3) and depression (Table 4), respectively.

\section{Correlations}

\begin{tabular}{|lll|l}
\hline & & Anxiety & Erectile dysfunction \\
Anxiety & Pearson Correlation & 1 & .013 \\
& Sig. (2-tailed) & & .905 \\
& $\mathrm{~N}$ & 84 & 84 \\
Erectile dysfunction & Pearson Correlation & .013 & 1 \\
\hline
\end{tabular}

\section{TABLE 3: Correlational analysis between anxiety and erectile dysfunction}

These correlations show positivity but without any significant p-values.

Significant $p$-value $(p<0.05)$

\section{Correlations}

\begin{tabular}{|c|c|c|c|}
\hline & & Erectile dysfunction & Depression \\
\hline \multirow{3}{*}{ Erectile dysfunction } & Pearson Correlation & 1 & .057 \\
\hline & Sig. (2-tailed) & & .603 \\
\hline & $\mathrm{N}$ & 84 & 84 \\
\hline \multirow{3}{*}{ Depression } & Pearson Correlation & .057 & 1 \\
\hline & Sig. (2-tailed) & .603 & \\
\hline & $\mathrm{N}$ & 84 & 84 \\
\hline
\end{tabular}

\section{TABLE 4: Correlational analysis between depression and erectile dysfunction}

These correlations show positivity but without any significant p-values.

Significant $p$-value $(p<0.05)$

Hence, we failed to reject the null hypothesis that there is no association between erectile dysfunction and associated anxiety and depression in male hemodialysis patients.

\section{Discussion}

Yu-Sen Peng et al. quoted the mean total IIEF score to be $49.1 \pm 17.6$, whereas our research shows a slightly lower mean total of $47.4 \pm 20.0$. The difference is probably suggestive of the variation in sample size being 154 , almost double as compared to ours [12].

It was noted in this study that the prevalence of ED in males was lower (47.6\%) as compared to the study done by Antonucci et al. who reported 70\% ED [3]. Gorsane et al. reported 80\% ED and Arslan et al. recorded 
an $80.7 \%$ prevalence of ED in males undergoing hemodialysis [13,6]. However, it was intriguing to discover that studies conducted way back in the 1970s like Abram et al. and those in the 1980s like Rodger et al. also noted the same pattern where ED prevailed in more than $50 \%$ of the patients $[14,15]$.

Possibly, the prevalence could be even much less had it not been for about a handful of patients who were not indulging in any sort of sexual activity to prevent the spread of other co-morbidities like hepatitis $\mathrm{C}$ to their spouses. There were a total of 15 (17.9\%) candidates who had hepatitis C and only 5 (33.3\%) of these suffered from ED. A total of four participants also had hepatitis B and three (75\%) of them were co-morbid with ED. It is stated that ED may have an increased incidence with the duration of hemodialysis; however, there has been no significant finding in this research that could support this theory.

Baldwin et al. study shows that there is an association of patients diagnosed with depression to have erectile dysfunction; however, this is not supported in this study [16]. Guven et al. did find a correlation between anxiety and education level, however, we could not tabulate any such findings with any of the known parameters [17]. Although there does seem to be some sort of positive correlation, there is no apparent significance to the theory, as shown in the research conducted by Esen et al. [18]. Paraskevi et al. did a study that revealed a negative correlation between ED and depression [19].

Theofilou et al. not only proved negative correlations between ED and depression but also anxiety proved to be significantly negatively correlated [19].

\section{Conclusions}

This study gives rise two main conclusions, namely, prevalence rate and association with depression and anxiety. We conclude that the prevalence rate is much lower than reported in other countries and depression and/or anxiety are not significantly correlated with erectile dysfunction. ED is seemingly thriving, and to find a light for this dwindling staircase into depression, anxiety, and maybe even infertility by natural methods is fundamental.

This study was conducted in a single center and comprised a fairly small number of patients. Nonetheless, the findings prompt multiple studies to verify and confirm that ED in the Pakistani population is relatively lower in hemodialysis patients as well as that it is not significantly linked to depression and anxiety. Followup studies are needed in the future for clearer results.

\section{Additional Information \\ Disclosures}

Human subjects: Consent was obtained by all participants in this study. Karachi Institute of Kidney Diseases issued approval not applicable. Here at the Karachi Institute of kidney diseases, we don't have formal IRB approval numbers for our research papers. But we do have an approval letter from the ethical committee of the Karachi Institute of Kidney Diseases authenticating the ethical standards of this research. It can be provided on demand. Animal subjects: All authors have confirmed that this study did not involve animal subjects or tissue. Conflicts of interest: In compliance with the ICMJE uniform disclosure form, all authors declare the following: Payment/services info: All authors have declared that no financial support was received from any organization for the submitted work. Financial relationships: All authors have declared that they have no financial relationships at present or within the previous three years with any organizations that might have an interest in the submitted work. Other relationships: All authors have declared that there are no other relationships or activities that could appear to have influenced the submitted work.

\section{References}

1. Kidney disease statistics for the United States . (2020). Accessed: September 25, 2020: https://www.niddk.nih.gov/health-information/health-statistics/kidney-disease.

2. Pereira BDS, Fernandes NDS, de Melo NP, Abrita R, Grincenkov FRDS, Fernandes NMDS: Beyond the quality of life: a cross-sectional study on the mental health of patients with chronic kidney disease undergoing dialysis and their caregivers. Health Qual Life Outcomes. 2017, 15:74. 10.1186/s12955-017-0646-4

3. Antonucci M, Palermo G, Recupero SM, et al.: Male sexual dysfunction in patients with chronic end-stage renal insufficiency and in renal transplant recipients. Arch Ital Urol Androl. 2016, 87:299-305. 10.4081/aiua.2015.4.299

4. Seftel AD, Sun P, Swindle R: The prevalence of hypertension, hyperlipidemia, diabetes mellitus, and depression in men with erectile dysfunction. J Urol. 2004, 171:2341-2345. 10.1097/01.ju.0000125198.32936.38

5. Impotence. NIH consens statement. 1992, 10:1-33.

6. Arslan D, Aslan G, Sifil A, Çavdar C, Çelebi İ, Gamsari T, Esen AA: Sexual dysfunction in male patients on hemodialysis: assessment with the International Index of Erectile Function (IIEF). Int J Impot Res. 2002, 14:539-542. 10.1038/sj.ijir.3900937

7. Hassan K, Elimeleh Y, Shehadeh M, Fadi H, Rubinchik I: The relationship between hydration status, male sexual dysfunction, and depression in hemodialysis patients. Ther Clin Risk Manag. 2018, 523-529. 10.2147/TCRM.S147723 
8. Davis D, Shaver PR, Widaman KF, Vernon MI, Follette WC, Beitz K: “I can't get no satisfaction”: insecure attachment inhibited sexual communication and sexual dissatisfaction. Pers Relationsh. 2006, 13:465-483.

9. Papadopoulou E, Varouktsi A, Lazaridis A, Boutari C, Doumas M: Erectile dysfunction in chronic kidney disease: from pathophysiology to management. World J Nephrol. 2015, 4:379-387. 10.5527/wjn.v4.i3.379

10. Procci WR, Goldstein DA, Adelstein J, Massry SG: Sexual dysfunction in the male patient with uremia: a reappraisal. Kidney Int. 1981, 19:317-323. 10.1038/ki.1981.22

11. Rosen RC, Riley A, Wagner G, Osterloh IH, Kirkpatrick J, Mishra A: The international index of erectile function (IIEF): a multidimensional scale for assessment of erectile dysfunction. Urology. 1997, 49:822-830. 10.1016/s0090-4295(97)00238-0

12. Peng YS, Chiang CK, Hung KY, et al.: The association of higher depressive symptoms and sexual dysfunction in male hemodialysis patients. Nephrol Dial Transplant. 2007, 22:857-861. 10.1093/ndt/gfl666

13. Gorsane I, Amri N, Younsi F, Helal I, Kheder A: Erectile dysfunction in hemodialysis patients. Saudi J Kidney Dis Transpl. 2016, 27:23-8. 10.4103/1319-2442.174057

14. Abram HS, Hester LR, Sheridan WF, Epstein GM: Sexual functioning in patients with chronic renal failure. J Nerv Ment Dis. 1975, 160:220-226. 10.1097/00005053-197503000-00007

15. Rodger RS, Fletcher K, Dewar JH, et al.: Prevalence and pathogenesis of impotence in one hundred uremic men. Uremia Invest. 1984-1985, 8:86-89. 10.3109/08860228409080989

16. Baldwin DS: Depression and sexual dysfunction. Br Med Bull. 2001, 57:81-99. 10.1093/bmb/57.1.81

17. Guven S, Sari F, Inci A, Cetinkaya R: Sexual dysfunction is associated with depression and anxiety in patients with predialytic chronic kidney disease. Eurasian J Med. 2018, 50:75-80. 10.5152/eurasianjmed.2018.17152

18. Esen B, Kahvecioglu S, Atay AE, et al.: Evaluation of the relationship between sexual functions, depression, and quality of life in patients with chronic kidney disease at the predialysis stage. Ren Fail. 2015, 2:262-267. 10.3109/0886022X.2014.990348

19. Theofilou P: Quality of life in patients undergoing hemodialysis or peritoneal dialysis treatment . J Clin Med Res. 2011, 3:132-138. 10.4021/jocmr552w 